\title{
Aeromonas cytotonic enterotoxin cross reactive with cholera toxin
}

\author{
J. POTOMSKI, VALERIE BURKE, JENNIFER ROBINSON, D. FUMAROLA* and \\ G. MIRAGLIOTTA*
}

\begin{abstract}
Gastroenterology and Nutrition Research Unit, Princess Margaret Children's Medical Research Foundation, Perth, Western Australia and "Institute of Medical Microbiology, University of Bari, 70124 Bari, Italy
\end{abstract}

Summary. Isolation by affinity chromatography from crude culture filtrate of Aeromonas sobria of protein that cross reacted with cholera toxin (CT) revealed a toxin that produced fluid accumulation in rat ileal loops and in infant mice and caused rounding of Y1 adrenal cells. All these activities were neutralised by antiserum to CT. There was no haemolytic or cytotoxic activity associated with this CT-cross reactive cytotonic enterotoxin. CT-cross reactive material detected in enzyme linked immunosorbent assay (ELISA) was produced by $25 \%$ of Aeromonas isolates from faeces of children with or without diarrhoea- $26 \%$ of $A$. sobria, $20.0 \%$ of $A$. hydrophila and $24 \%$ of $A$. caviae tested gave positive ELISA results. Most strains that produced this cytotonic enterotoxin but no cytotoxic enterotoxin were isolated from children without diarrhoea. Toxin preparations from Aeromonas spp. that completely inhibited adenosine-5'-diphosphate-induced platelet aggregation, an effect related to elevation of intracellular cAMP, were, with one exception, cross reactive with CT in ELISA.

\section{Introduction}

Immunological cross-reactivity between cholera toxin (CT) and the heat labile toxin (LT) of Escherichia coli is well recognised (Clements and Finkelstein, 1978). The investigation of other bacteria for toxins cross reactive with $\mathrm{CT}$ suggests that there is a family of CT-like enterotoxins that may be produced by Klebsiella pneumoniae and Enterobacter cloacae (Klipstein and Engert, 1977), Salmonella spp. (Sandefur and Peterson, 1977) and Campylobacter jejuni (Ruiz-Palacios et al., 1983).

Reports of CT-like activity of Aeromonas spp. have been inconsistent. Wadstrom et al. (1976) initially found that antiserum to CT or LT partially inhibited aeromonas enterotoxin and that there was a single precipitin line with antisera to CT in immunodiffusion studies with aeromonas enterotoxin (Ljungh et al., 1977). However, they were unable to confirm their findings. Boulanger et al. (1977) failed to neutralise the effects of aeromonas enterotoxin in rabbit ileal loop or suckling mouse assays but Dobrescu (1978), James et al. (1982) and Jiwa (1983) demonstrated cross reactions between exotoxins of Aeromonas spp. and LT or CT. This

Received 19 Feb. 1986; accepted 26 Jun. 1986. apparent conflict probably reflects the multiplicity of extracellular products of Aeromonas spp. present in crude culture filtrates. It is now clear, for example, that both cytotoxic (Asao et al., 1984) and cytotonic (Chakraborty et al., 1984) enterotoxins of Aeromonas spp. are capable of producing fluid accumulation in suckling mice, so that the use of such a model would not allow detection of neutralisation of one toxin in the presence of the other.

More recently immunologically-based assays have demonstrated CT-like activity produced by strains of Aeromonas spp. (Shimada et al., 1984; Campbell and Houston, 1985). Shimada et al. (1984) did not report biological activity related to this CT-reactive product and, although Campbell and Houston (1985) showed fluid accumulation in rabbit ileal loops with culture filtrates that cross reacted with $\mathrm{CT}$, they failed to demonstrate that this enterotoxicity was associated with the CTreactive fraction and not with cytotoxic enterotoxicity. In the present study we have used enzyme linked immunosorbent assay (ELISA) to detect CTlike activity and affinity chromatography to isolate a CT-cross reactive protein produced by faecal isolates of Aeromonas spp., and we have related the results to species, production of cytotoxic enterotoxin and the presence of diarrhoea. 


\section{Materials and methods}

\section{Bacteria}

Four strains of Aeromonas spp. known to produce CTlike activity were kindly provided by $\mathrm{Dr}$ R. Sakazaki of the Department of Bacteriology, National Institute of Health, Kamiosaki, Tokyo. Three were $A$. sobria and one A. hydrophila (Popoff, 1984). All other strains were isolated from faeces of children with or without diarrhoea during 1980-1981 in a study reported elsewhere (Gracey et al., 1982). All strains isolated by primary culture on blood agar, as well as those isolated only after enrichment in nutrient broth or alkaline peptone water, were included in this study. Of the 205 strains isolated, 143 were $A$. sobria, 25 A. hydrophila and $37 A$. caviae when classified according to Popoff (1984).

Strains were stored in 3-ml volumes of maintenance medium consisting of agar $5 \mathrm{~g}, \mathrm{NaCl} 5 \mathrm{~g}$, peptone 0118 (Difco) $2.5 \mathrm{~g}$, peptone L32 (Oxoid) $2.5 \mathrm{~g}$ in $200 \mathrm{ml}$ of PBS (containing $\mathrm{Na}_{2} \mathrm{HPO}_{4} 2.8 \mathrm{~g}$ in $134 \mathrm{ml}$ of distilled water and $\mathrm{KH}_{2} \mathrm{PO}_{4} 1.3 \mathrm{~g}$ in $66 \mathrm{ml}$ of distilled water), and $800 \mathrm{ml}$ of distilled water, $p \mathrm{H} \mathrm{6.7.}$

\section{Bacterial preparations}

For assay of biological activity and for production of crude CT-like toxin, Aeromonas spp. were grown in Tryptone Soya Broth (Oxoid) supplemented with yeast extract (Oxoid) $0.6 \%$ shaken at $300 \mathrm{rpm}$ in an environmental incubator shaker (New Brunswick Scientific, Edison, NJ, USA) at $37^{\circ} \mathrm{C}$ for $22 \mathrm{~h}$. Sterile broth filtrates for the biological tests were obtained by centrifugation at $2000 \mathrm{~g}$ for $10 \mathrm{~min}$ at $4^{\circ} \mathrm{C}$ and filtration through $0.45-\mu \mathrm{m}$ membrane filters (Millipore) and were stored at $4^{\circ} \mathrm{C}$ until tested, within $24 \mathrm{~h}$ of preparation.

\section{Biological assays}

Suckling-mouse tests were performed as described by Burke et al. (1981); an intestinal weight/body weight (IW/BW) ratio of $\geq 0.08$ was the criterion of a positive result. For routine testing of Aeromonas spp., three mice were used for each test with two tests per sample. With the cytotonic enterotoxin isolated by affinity chromatography, we used six mice for each test with two tests per sample. As fluid secretion in infant mice challenged with CT does not occur as quickly as the response to $E$. coli heat stable toxin (STa) (Baselski et al., 1977), groups of mice were held for the usual period of $3 \mathrm{~h}$ or for $5 \mathrm{~h}$.

The rat ileal loop test was performed as described by Pierce (1977) with at least two rats for each test. Results were expressed as $\mathrm{ml}$ of fluid/cm of intestine; values greater than $0.2 \mathrm{ml} / \mathrm{cm}$ were considered positive.

Cytotonicity and cytotoxicity tests. Y1 cells were used for assay of cytotonicity and L132 cells for assay of cytotoxicity (Donta et al., 1974). For titration, $25 \mu \mathrm{l}$ of the toxin diluted with PBS were added to $100 \mu l$ of cell monolayers in 96-well microculture plates (Linbro, Flow Laboratories, Irvine, Ayrshire) and incubated for $18 \mathrm{~h}$ in $\mathrm{CO}_{2} 5 \%$ at $37^{\circ} \mathrm{C}$. The response was considered to be cytotonic if there was rounding of $>50 \%$ of cells or cytotoxic if there was death of $>50 \%$ of cells.

Haemolytic activity was assayed as described previously (Burke et al., 1984b). Lysis of at least $50 \%$ of the erythrocytes was considered a positive result.

\section{Definition of enterotoxin activity}

Production of cytotoxic enterotoxin was defined by cytotoxicity in cell culture, a positive haemolysin assay and IW/BW ratio $>0.08$, in the suckling-mouse test. Cytotonic enterotoxin was recognised by cross reactivity with CT in ELISA and a positive suckling-mouse test. Cytotonic effects in $\mathrm{Y} 1$ cells could be recognised in the presence of cytotoxic enterotoxin by heating cell-free supernates to $56^{\circ}$ for $20 \mathrm{~min}$ before addition to cell cultures (Chakraborty et al., 1984). Results in Y1 cells were concordant with results in ELISA so that, in subsequent discussion, this cytotonic enterotoxin is considered to be the material detected in ELISA.

\section{Assay for cross reactivity with $C T$}

Immunisation procedures. Antisera to $\mathrm{CT}$ were produced by repeated inoculations of purified toxin (CalbiochemBehring, La Jolla, CA, USA) into a sheep and a rabbit. Animals were given primary immunisation subcutaneously with Freund's complete adjuvant and two subcutaneous booster immunisations at monthly intervals with Freund's incomplete adjuvant. The doses of CT for primary and booster immunisations in the sheep were 60 , 40 and $40 \mu \mathrm{g}$. In the rabbit the respective doses were 10 , 5 and $5 \mu \mathrm{g}$ of CT.

Enzyme-linked immunosorbent assay (ELISA). The assay was performed as described by Yolken et al. (1977). The optimal dilutions of reagents were first determined by chessboard titration. All samples were tested in triplicate, working volumes were $100 \mu$, and all dilutions of antigens and antisera were made with phosphatebuffered saline-Tween- $0 \cdot 1 \%$ bovine serum albumin buffer. This buffer contained $\mathrm{NaCl} 8 \mathrm{~g}, \mathrm{KH}_{2} \mathrm{PO}_{4} 0 \cdot 2 \mathrm{~g}$, $\mathrm{Na}_{2} \mathrm{HPO}_{4} 1.14 \mathrm{~g}, \mathrm{KCl} 0.2 \mathrm{~g}, \mathrm{NaN}_{3} 0.2 \mathrm{~g}$ and Tween 20 $0.5 \mathrm{ml} / \mathrm{L}$ of distilled water, $p \mathrm{H} \mathrm{7.4}$. Bovine serum albumin was added to give a final concentration of $0 \cdot 1 \%$. Sheep anti-cholera toxin serum was used as the solid phase, diluted rabbit antiserum to cholera toxin as the second antibody, and alkaline phosphate-conjugated goat antirabbit IgG antiserum (Miles Laboratories, Rehovot, Israel) was used as the conjugate. Coated plates were stored at $-20^{\circ} \mathrm{C}$ until use to maintain optimal sensitivity of the assay. Optical densities at $405 \mathrm{~nm}$ were determined with Titertek Multiscan automatic spectrophotometer. Values greater than twice the optical density of the control were considered positive.

\section{Platelet aggregation test (PAT)}

Twenty strains were used for comparison of the PAT with results of ELISA: $A$. sobria $11, A$. hydrophila 7 and A. caviae 2 . 
Platelet aggregation is influenced by compounds that affect intracellular levels of AMP (Salzman, 1972). Enterotoxins which increase intracellular cAMP inhibit platelet aggregation. This inhibition of ADP-induced platelet aggregation is the basis for the use of the PAT for assay of cAMP-mediated enterotoxins (Fumarola and Miragliotta, 1981).

Bacterial preparation. Aeromonas strains were grown in screw-cap tubes containing $5 \mathrm{ml}$ of Trypticase Soy Broth (BBL 11767) with yeast extract (Difco 0127) 0.6\% for $48 \mathrm{~h}$ at $37^{\circ} \mathrm{C}$ on a roller drum $(60 \mathrm{rpm})$ with the tubes nearly horizontal. Cultures were centrifuged and the supernates were filtered through $0 \cdot 45-\mu \mathrm{m}$ membrane filters (Millipore). Filtrates were endotoxin free as shown by the Limulus gelation assay.

Preparation of platelets. Normal donors who had received no medication such as aspirin in the 10 days preceding venepuncture provided the platelets. Trisodium citrate $(3.8 \%)$ in a ratio of $10: 1 \mathrm{v}: \mathrm{v}$ was used as the anticoagulant. Citrated platelet-rich plasma was separated by centrifugation at $100 \mathrm{~g}$ for $20 \mathrm{~min}$ at room temperature and platelet-deficient plasma was obtained by sedimentation of platelets from samples of the platelet rich preparation at $250 \mathrm{~g}$ for $20 \mathrm{~min}$. The platelet count in the platelet-rich plasma was adjusted to $300000 / \mu \mathrm{l}$ by dilution with platelet-deficient plasma.

Platelet aggregation. The photometric technique of Born (1962) with an Elvi 840 Aggregometer (Elvi Logos, Milan, Italy) was used to measure platelet aggregation at $37^{\circ} \mathrm{C}$. Platelet rich plasma from each donor was incubated in $0.3-\mathrm{ml}$ volumes with $0.1 \mathrm{ml}$ of each bacterial filtrate. Saline and cholera toxin were, respectively, the negative and positive controls. After incubation for $15 \mathrm{~min}$, samples were challenged with $1 \cdot 8-6 \cdot 4 \mu \mathrm{mol}$ of adenosine5 ' diphosphate, disodium salt (ADP Sigma, St Louis, MO, USA) as the aggregating agent. Failure to aggregate platelets, as seen with CT, produced no increase in the percentage transmission measured photometrically.

\section{Preparation of cytotonic enterotoxin}

A strain of $A$. sobria isolated from faeces of a patient with diarrhoea was used as the source of the CT-cross reactive enterotoxin. Solid ammonium sulphate was added to the cell-free supernate to $60 \%$ of saturation at $4^{\circ} \mathrm{C}$. The precipitate was left at $4^{\circ} \mathrm{C}$ overnight and then was collected by centrifugation at $13500 \mathrm{~g}$ for $20 \mathrm{~min}$, dissolved in and dialysed against phosphate-buffered saline (PBS) $p \mathrm{H} 7.3$ and kept frozen at $-70^{\circ} \mathrm{C}$ until use. This material is referred to as crude enterotoxin.

Protein determination. Protein content was determined as described by Read and Northcote (1981) with bovine serum albumin as a standard.

Immunoadsorption. The $\gamma$ globulin of sheep anti-serum to $\mathrm{CT}$, precipitated at room temperature with $40 \%$ saturated ammonium sulphate, was dissolved in PBS, dialysed against $10 \mathrm{mM}$ Tris- $\mathrm{HCl}$ buffer, $p \mathrm{H} 8 \cdot 0$, (starting buffer) at $4^{\circ} \mathrm{C}$ overnight and loaded onto the DEAE Sephacel (Pharmacia Fine Chemicals, Uppsala, Sweden) column equilibrated with the same buffer. The column was eluted with linear gradient of $0-300 \mathrm{mM} \mathrm{NaCl}$ in starting buffer. Fractions containing IgG were pooled, concentrated by ultrafiltration and equilibrated against $0 \cdot 1 \mathrm{M}$ sodium bicarbonate, $p \mathrm{H} 10 \cdot 0$. A portion containing $225 \mathrm{mg}$ of protein was mixed with $10 \mathrm{ml}$ of $1,1^{\prime}$-carbonyldi-imidazole activated agarose (Reacti-Gel, Pierce Chemical Company, Rockford, IL, USA) and tumbled overnight at $4^{\circ} \mathrm{C}$. Active groups were blocked by the addition of $1.0 \mathrm{M}$ ethanolamine at $p \mathrm{H} 9.0$ for $3 \mathrm{~h}$ at room temperature. After washing with water, $1 \mathrm{M} \mathrm{NaCl}$, water and PBS, the coupled gel was poured into a column to which crude enterotoxin was added. After washing with

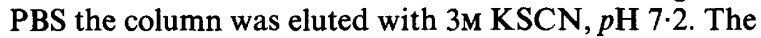
eluted protein was dialysed against PBS, concentrated by ultrafiltration and stored at $-70^{\circ} \mathrm{C}$. The column was regenerated by washing with PBS.

$S D S-P A G E$ on gradient gels. The eluted protein was analysed by electrophoresis on slabs of acrylamide 2.5$27 \%$ gradient (Gradient Laboratories, Pyrmont, Australia) in the presence of sodium dodecyl sulphate (SDSPAGE) (Lambin, 1978). The gel was stained with Coomassie brilliant blue R250 (Bio-Rad Laboratories, Richmond, CA, USA) and then destained. Mol.-wt markers (Pharmacia, Uppsala, Sweden) were included.

\section{Neutralisation tests}

Equal volumes of the purified enterotoxin $(20 \mu \mathrm{g} / \mathrm{ml})$ and anti-CT serum were mixed, incubated for $60 \mathrm{~min}$ at $37^{\circ} \mathrm{C}$, and assayed in ileal loops, suckling mice and $\mathrm{Y} 1$ cells.

\section{Results}

\section{Isolation of the CT-cross reactive product}

Before the application of crude aeromonas enterotoxin, the ability of the column to bind CT was assessed. The capacity of the column, as indicated by depletion of applied CT and its recovery from the column, was at least $150 \mu \mathrm{g}$ of CT.

When the crude enterotoxin of $A$. sobria was applied to the column, the protein reacting in ELISA with antiserum to CT was retained. Only $5 \%$ of the adsorbed protein was eluted with $0.1 \mathrm{M}$ glycine- $\mathrm{HCl}$ buffer, $p \mathrm{H} 2 \cdot 5$. The rest of the bound material was eluted with $3 \mathrm{M} \mathrm{KSCN}$ and subsequently only this material was used in the study.

This eluted product had about $10 \%$ of the biological activity of the crude enterotoxin. No activity was detectable in the suckling-mouse test, rat ileal loop test or in $\mathrm{Y} 1$ cells at a concentration of $2 \mu \mathrm{g} / \mathrm{ml}$ but at a concentration of $10 \mu \mathrm{g} / \mathrm{ml}$ this product showed activity in all of these test systems.

In the suckling-mouse test, the IW/BW ratio was 0.82 after incubation for $3 \mathrm{~h}$ with the eluted material 
in a concentration of $10 \mu \mathrm{g} / \mathrm{ml}$. Pre-incubation with antiserum to $C T$ produced an IW/BW ratio of 0.055 . With samples incubated in suckling mice for $5 \mathrm{~h}$, the eluted material produced an IW/BW ratio of 0.12 and after pre-incubation with cholera antitoxin the IW/BW ratio was $0 \cdot 07$.

In the rat ileal-loop test, the eluted product in a concentration of $10 \mu \mathrm{g} / \mathrm{ml}$, resulted in a mean fluid accumulation of $0.27 \mathrm{ml} / \mathrm{cm}$ (SEM 0.01). In loops containing this product pre-incubated with cholera antiserum, mean fluid accumulation was $0.11 \mathrm{ml} /$ cm (SEM 0.02).

The addition of the product to $\mathrm{Y} 1$ cells produced rounding (fig. 1a) which was neutralised by cholera antitoxin (fig. 1b). No cytotoxic or haemolytic activity was demonstrated.

In SDS-PAGE without reducing agent, the material eluted with $3 \mathrm{M} \mathrm{KSCN}$ showed three major protein bands (fig. 2) with apparent mol. wts $\left(10^{3}\right)$ $43.5,29.5$ and $27 \cdot 0$. A protein of high mol. wt, beyond the range of the markers used, was also detected. By extrapolation its mol. wt was estimated at $150 \times 10^{3}$. Treatment with 2-mercaptoethanol did not change the electrophoretic pattern of the eluted material.

\section{Screening for CT-cross reactive cytotonic enterotoxin}

Of the 205 faecal isolates of Aeromonas spp. tested, toxin preparations from $51(25 \%)$ cross reacted with CT in ELISA. The distribution of species (table I) was not significantly different between ELISA-negative and ELISA-positive strains $\left(\chi^{2}\right.$ test, $\left.p>0.05\right)$. Strains positive in ELISA were $26 \%$ of the $A$. sobria strains, $20 \%$ of $A$. hydrophila and $24 \%$ of $A$. caviae tested.

The relationship between production of cytotoxic and cytotonic enterotoxin is shown in table II. All but 11 strains ( $2 A$. hydrophila and $9 A$. caviae) that produced cytotonic enterotoxin also produced cytotoxic enterotoxin. Results were positive in the suckling-mouse assay if strains produced either or both enterotoxins. All positive results were detected

Table I. Cytotonic enterotoxin detected by ELISA in relation to species

\begin{tabular}{l|ccc}
\hline & \multicolumn{3}{|c}{$\begin{array}{c}\text { Number of isolates }(\%) \text { that gave the } \\
\text { indicated result }\end{array}$} \\
\cline { 2 - 4 } ELISA result & $\begin{array}{r}\text { A. sobria } \\
(\mathrm{n}=143)\end{array}$ & $\begin{array}{c}\text { A. hydrophila } \\
(\mathrm{n}=25)\end{array}$ & $\begin{array}{c}\text { A. caviae } \\
(\mathrm{n}=37)\end{array}$ \\
\hline $\begin{array}{l}\text { Positive }(\mathrm{n}=51) \\
\text { Negative }(\mathrm{n}=154)\end{array}$ & $\begin{array}{r}37(26) \\
106(74)\end{array}$ & $\begin{array}{r}5(20) \\
20(80)\end{array}$ & $\begin{array}{r}9(24) \\
28(76)\end{array}$ \\
\hline
\end{tabular}

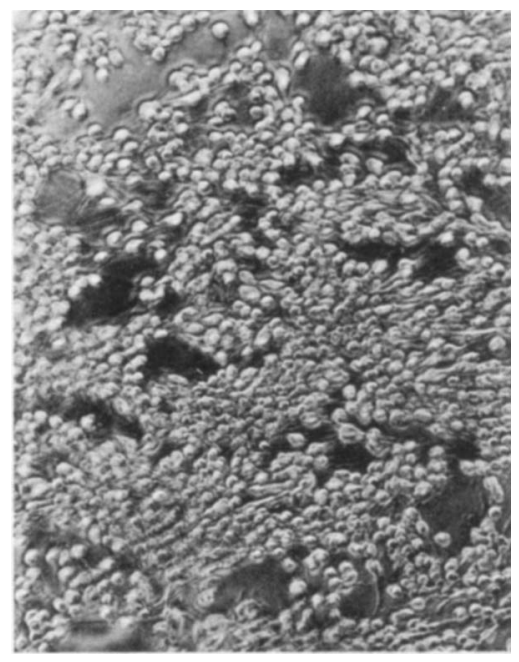

Fig. 1a. Rounding of $Y 1$ cells produced by the toxin isolated by affinity chromatography $(\times 100)$.

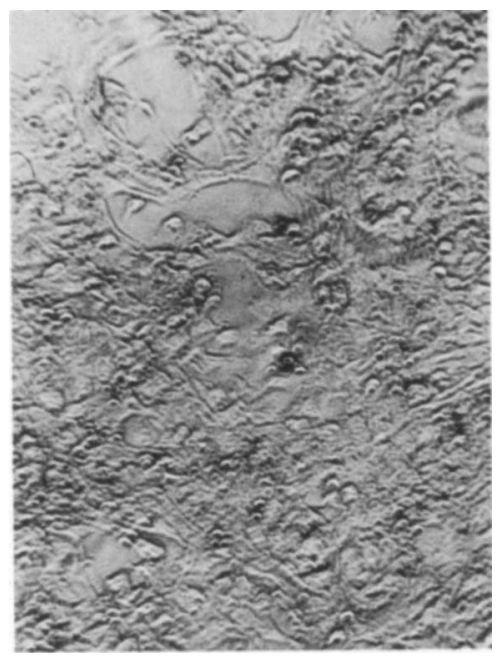

Fig. 1b. Neutralisation of cytotonic effects on Y1 cells by pre-incubation of the toxin with antiserum to $C T(\times 100)$.

after incubation for $3 \mathrm{~h}$ and, although the IW/BW ratio increased after incubation for $5 \mathrm{~h}$, no strains gave negative results at $3 \mathrm{~h}$ and positive results after $5 \mathrm{~h}$.

Most of the strains that were positive in ELISA were associated with diarrhoea (table III) but all except 11 of these strains also produced cytotoxic enterotoxin (table II). There was a similar association between diarrhoea and production of cytotoxic enterotoxin amongst strains that did not produce cytotonic enterotoxin, i.e., epidemiological data did not suggest that diarrhoea occurred more frequently when strains produced both enterotoxins. Of the 11 


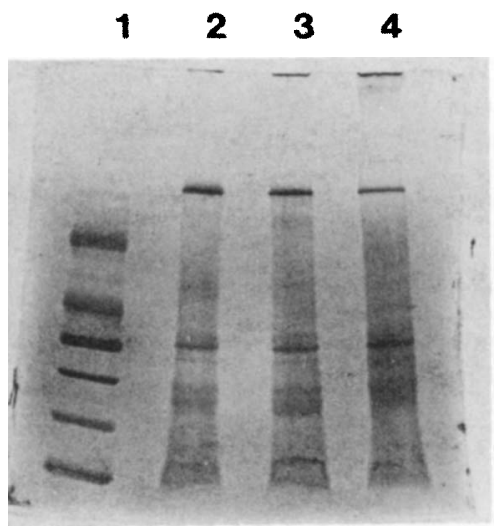

Fig. 2. Sodium dodecyl sulphate-polyacrylamide gradient gel electrophoresis (SDSPAGE) of the isolated enterotoxin $(10 \mu \mathrm{g})$. Lane 1, mol. wt reference proteins: from the top of the gel these proteins were phosphorylase b $(94000)$, bovine serum albumin $(67000)$, ovalbumin $(43000)$, carbonic anhydrase $(30000)$, soybean trypsin inhibitor $(20100)$, and lactalbumin (14 400); lane 2, sample heated at $100^{\circ} \mathrm{C}$ for $5 \mathrm{~min}$ in the absence of mercaptoethanol; lane 3 , sample incubated at $37^{\circ} \mathrm{C}$ for $3 \mathrm{~h}$ in the presence of mercaptoethanol $5 \%$; lane 4 , sample heated at $100^{\circ} \mathrm{C}$ for $5 \mathrm{~min}$ in the presence of mercaptoethanol $5 \%$.

strains that produced cytotonic but not cytotoxic enterotoxin, only one $A$. caviae strain was associated with diarrhoea, in a patient from whom a salmonella was isolated from the same faecal specimen.

\section{Platelet aggregation test}

Eight strains inhibited platelet aggregation completely. Only one of these strains gave negative results in ELISA, but the optical density attained with this strain was consistently just below twice

Table II. Cytotonic enterotoxin detected by ELISA in relation to suckling-mouse tests, production of cytotoxic enterotoxin, and species

\begin{tabular}{|c|c|c|c|c|c|c|c|}
\hline \multirow[b]{3}{*}{$\begin{array}{l}\text { ELISA } \\
\text { result }\end{array}$} & \multirow{3}{*}{$\begin{array}{l}\text { Positive } \\
\text { result in } \\
\text { suckling- } \\
\text { mouse test }\end{array}$} & \multicolumn{6}{|c|}{ Cytotoxic enterotoxin test } \\
\hline & & \multicolumn{3}{|c|}{ Positive } & \multicolumn{3}{|c|}{ Negative } \\
\hline & & $\mathbf{S}$ & $\mathbf{H}$ & $\mathrm{C}$ & $\mathbf{S}$ & $\mathbf{H}$ & $\mathrm{C}$ \\
\hline $\begin{array}{l}\text { Positive } \\
(n=51) \\
\text { Negative } \\
(n=154)\end{array}$ & $\begin{array}{r}51 \\
123\end{array}$ & $\begin{array}{r}37 \\
105\end{array}$ & 3 & 0 & 0 & 2 & 28 \\
\hline
\end{tabular}

$\mathrm{S}=$ A. sobria, $\mathrm{H}=$ A. hydrophila, $\mathrm{C}=A$. caviae .
Table III. Cytotonic enterotoxin detected by ELISA related to the presence of diarrhoea

\begin{tabular}{|c|c|c|c|c|}
\hline \multirow[b]{3}{*}{ ELISA result } & \multicolumn{4}{|c|}{$\begin{array}{l}\text { Number of strains in which cytotonic } \\
\text { enterotoxin was detected }\end{array}$} \\
\hline & A. sobria & \multicolumn{2}{|c|}{ A. hydrophila } & A. caviae \\
\hline & $\mathrm{D}^{+} \quad \mathrm{D}^{-}$ & $\mathbf{D}^{+}$ & $\mathbf{D}^{-}$ & $\mathbf{D}^{+} \quad \mathbf{D}^{-}$ \\
\hline $\begin{array}{l}\text { Positive }(n=51) \\
\text { Negative }(n=154)\end{array}$ & $\begin{array}{l}28(2)^{*} \quad 9(7) \\
74(5) \quad 32(28)\end{array}$ & $\begin{array}{l}3 \\
12(2)\end{array}$ & $\begin{array}{l}2 \\
8(6)\end{array}$ & $\begin{array}{lr}1 & 8(1) \\
6(1) & 22(2)\end{array}$ \\
\hline
\end{tabular}

$\mathrm{D}^{+}$diarrhoea, $\mathrm{D}^{-}$no diarrhoea.

* Numbers in parenthesis are numbers of strains isolated after enrichment but not on primary culture.

the control value, the criterion chosen for a positive result in ELISA. Five strains partially inhibited platelet aggregation but gave negative results in ELISA. The remaining seven strains tested in PAT did not inhibit platelet aggregation and showed no CT-like activity in ELISA (table IV).

The effect on platelet aggregation did not correlate with production of cytotoxic enterotoxin. Of the eight strains that completely inhibited platelet aggregation, two produced only cytotonic enterotoxin and six produced both cytotonic and cytotoxic enterotoxin. Of the seven strains that caused no inhibition of platelet aggregation, four produced cytotoxic enterotoxin in high titre.

\section{Discussion}

About one-quarter of Aeromonas spp. isolated from faeces produced cytotonic enterotoxin that cross reacted with CT in ELISA. Production of cytotonic enterotoxin was not associated with a particular biotype. Shimada et al. (1984) found that

Table IV. Comparison of results in platelet aggregation tests and ELISA

\begin{tabular}{l|cc}
\hline & \multicolumn{2}{|c}{ ELISA result } \\
\cline { 2 - 3 } Platelet aggregation test result & Positive & Negative \\
\hline Inhibition & $7(5)^{*}$ & $1+(1)$ \\
Partial inhibition & 0 & $5(3)$ \\
No inhibition & 0 & $7(4)$ \\
\hline
\end{tabular}

* Numbers in parenthesis are numbers of producers of cytotoxic enterotoxin.

$\uparrow$ This strain consistently produced optical-density readings just below the critical value for classification as positive in ELISA. 
all their CT-positive strains were " $A$. hydrophila", a group that would include both $A$. hydrophila and $A$. sobria if strains were classified according to Popoff (1984). They found no CT-positive $A$. caviae but, in our study, $24 \%$ of $A$. caviae strains were CTpositive. We have previously found that $A$. caviae rarely show potential virulence factors such as production of cytotoxic enterotoxin, fucose-resistant haemagglutination (Burke et al., 1984a) or invasiveness (Watson et al., 1985), consistent with the reported low virulence of this species (Schubert, 1967). Production of cytotonic enterotoxin appears to be more common than these other potential virulence factors in $A$. caviae. However, only one of the $A$. caviae strains that gave positive results in ELISA was associated with diarrhoea, and in that patient a salmonella was isolated from the same faecal sample.

It may be that diarrhoea is associated with cytotonic enterotoxin only if the Aeromonas strain also possesses the required colonisation factors, analogous to the situation with enterotoxigenic $E$. coli (Satterwhite et al., 1978). None of the A. caviae strains that gave positive results in ELISA showed fucose-resistant haemagglutination, the pattern, in our experience, most commonly produced by strains isolated from patients with Aeromonas-associated diarrhoea (Burke et al., 1984a).

Diarrhoea was associated with the production of cytotoxic enterotoxin, both in strains that produced cytotonic enterotoxin and those that did not. Because we found so few strains that produced only cytotonic enterotoxin, it has not been possible to assess the possible contribution of the cytotonic enterotoxin as a virulence factor in Aeromonas spp. However, data from the 11 non-cytotoxic, cytotonic enterotoxin-producing strains suggest that the cytotonic enterotoxin alone is not a virulence factor for aeromonads.

ADP induced platelet aggregation is known to be inhibited by substances that increase levels of intracellular cAMP in platelets (Salzman, 1972). CT, LT and salmonella CT-like enterotoxins, but not heat stable toxins of E. coli, Klebsiella or Yersinia enterocolitica, inhibit platelet aggregation (Fumarola and Miragliotta, 1983). Results in the platelet aggregation test with Aeromonas spp. are consistent with the suggestion that Aeromonas enterotoxins may act by increasing intracellular cAMP (Dubey et al., 1981; Fumarola and Miragliotta, 1984).

The ability to inhibit platelet aggregation was distinct from production of cytotoxic enterotoxin but there was good correlation between strains that gave positive results in ELISA and the ability to completely inhibit platelet aggregation. The single strain that completely inhibited platelet aggregation but was classified as negative in ELISA, consistently just failed to attain the critical value for a positive test, suggesting that the cytotonic enterotoxin was present in low concentrations. This observation, and the failure of strains causing partial inhibition in the PAT to be positive in ELISA, suggests that PAT is a more sensitive assay than ELISA for the cytotonic enterotoxin. However, the usefulness of PAT as a routine assay is limited by the difficulty of acquiring constant fresh supplies of human platelets from donors not exposed to drugs such as aspirin.

Shimada et al. (1984) presented evidence of immunological cross reactivity between CT and some strains of Aeromonas but did not establish that this CT-like toxin had biological activity. The enterotoxicity demonstrated in CT-cross reactive culture filtrates of $A$. hydrophila (Campbell and Houston, 1985) was not distinguished from the possible effect of cytotoxic enterotoxin that may have been present in the same preparation. By isolation of the CT-cross reactive material of $A$. sobria by affinity chromatography we have shown that this protein has the properties of a cytotonic enterotoxin, neutralised by antiserum to CT. There was no cytotoxicity or haemolytic activity associated with this cytotonic enterotoxin. We have shown previously that this same strain of $A$. sobria also produces a cytotoxic enterotoxin that causes fluid accumulation in rat ileal loops and in infant mice and is cytotoxic and haemolytic but none of these activities is neutralised by antiserum to CT. Thus, we have evidence to support the view that Aeromonas spp. may produce a cytotonic enterotoxin that cross reacts with $\mathrm{CT}$ and a cytotoxic enterotoxin that does not cross react with $\mathrm{CT}$. Both toxins are detectable in rat ileal loops and in infant mice (Asao et al., 1984; Chakraborty et al., 1984) but the cytotoxic enterotoxin is easily distinguished by its haemolytic or cytotoxic activity.

The relationship of the CT-cross reactive cytotonic enterotoxin we have isolated to the aeromonas cytotonic enterotoxins previously described is not clear. The enterotoxin isolated by Ljungh et al. (1981) does not cross react with CT, does not cause fluid accumulation in suckling mice and has a mol. wt of only 15000 but the cytotonic enterotoxin we isolated cross reacts with CT and causes fluid accumulation in suckling mice.

Chakraborty et al. (1984) have cloned an aeromonas cytotonic enterotoxin without haemolytic or cytotoxic activity that, like the cytotonic enterotoxin we have isolated, causes fluid accumulation in suckling mice but its mol. wt and ability to cross 
react with CT have not been reported. Genetic probing failed to show homology with $E$. coli heat labile toxin (LT) but CT was not investigated (Chakraborty et al., 1984).

It may be that apparent differences between these cytotonic enterotoxins of Aeromonas spp. reflect technical differences between laboratories. However, we used cross reactivity with CT as the basis for purification of this cytotonic enterotoxin and we cannot exclude the possibility of other cytotonic enterotoxins of Aeromonas spp. that do not react with $\mathrm{CT}$.

The need to use $3 \mathrm{M} \mathrm{KSCN}$ for elution of the bound protein from the column resulted in a considerable decrease in biological activity, in agreement with findings reported for affinity purification of LT (Dafni et al., 1978). Incubation of a crude LT preparation with 3M KSCN decreased biological activity by 10-90\% (Dafni et al., 1978).

SDS-PAGE identified four bands in the eluate. Dafni and Robbins (1976) and Dafni et al (1978) also found multiple bands on SDS-PAGE analysis

\section{REFERENCES}

Asao T, Kinoshita Y, Kozaki S, Uemura T, Sakaguchi G 1984 Purification and some properties of Aeromonas hydrophila hemolysin. Infection and Immunity 46: 122-127.

Baselski V, Briggs R, Parker C 1977 Intestinal fluid accumulation induced by oral challenge with Vibrio cholerae or cholera toxin in infant mice. Infection and Immunity 15: 704-712.

Born G V R 1962 Aggregation of blood platelets by adenosine diphosphate and its reversal. Nature 194: 927-929.

Boulanger Y, Lallier R, Cousineau G 1977 Isolation of enterotoxigenic Aeromonas from fish. Canadian Journal of Microbiology 23: 1161-1164.

Burke V et al. 1984a Hemagglutination patterns of Aeromonas spp. in relation to biotype and source. Journal of Clinical Microbiology 19: 39-43.

Burke V, Robinson J, Berry R J, Gracey M 1981 Detection of enterotoxins of Aeromonas hydrophila by a suckling mouse test. Journal of Medical Microbiology 14 : 401-408.

Burke V et al. $1984 b$ Biotyping and virulence factors in clinical and environmental isolates of Aeromonas spp. Applied and Environmental Microbiology 47: 1146-1149.

Campbell J D, Houston C W 1985 Effect of cultural conditions on the presence of a cholera-toxin cross reactive factor in culture filtrates of Aeromonas hydrophila. Current Microbiology 12: 101-106.

Chakraborty T, Montenegro M A, Sanyal S C, Helmuth R, Bulling E, Timmis K N 1984 Cloning of enterotoxin gene from Aeromonas hydrophila provides conclusive evidence of production of a cytotonic enterotoxin. Infection and Immunity 46 : 435-441.

Clements J D, Finkelstein R A 1978 Immunological crossreactivity between a heat-labile enterotoxin(s) of Escherichia coli and subunits of Vibrio cholerae enterotoxin. Infection and Immunity 21 : 1036-1039.

Dafni Z, Robbins J B 1976 Purification of heat-labile enterotoxin of LT-including components with apparent mol. wt similar to the A (mol. wt 27000 ) and B (mol. wt 58000 ) subunits of CT. The multiple bands found with the cytotonic enterotoxin of $A$. sobria are consistent with an analogous separation into subunits. Unlike the high mol.-wt band described by Dafni et al. (1978) the fraction of high mol. wt found on SDS-PAGE of Aeromonas cytotonic enterotoxin is probably not immunoglobulin because it was unaffected by the presence of reducing agent. It is not known whether this band represents undissociated enterotoxin.

At present, the relative importance of cytotonic and cytotoxic enterotoxins as virulence factors for Aeromonas spp. is not known and clarification awaits the development of an experimental model for Aeromonas-associated diarrhoea.

This work was supported by the TVW Telethon Foundation, Perth, and in part by the C.N.R., Italy, 1985 Progetto finalizzato Controllo Malattie da Infezione (Grant no. 85.00850.52). We thank Jan Beaman, Christine Groessler, Maggie Cooper and Ian Watson for technical assistance. from Escherichia coli $\mathrm{O} 78$ : $\mathrm{H} 11$ by affinity chromatography with antiserum to Vibrio cholerae toxin. Journal of Infectious Disease 133 Supplement S138-S141.

Dafni Z, Sack R B, Craig J P 1978 Purification of heat-labile enterotoxin from four Escherichia coli strains by affinity immunoadsorbent: evidence for similar subunit structure. Infection and Immunity 22: 852-860.

Dobrescu L 1978 Enterotoxigenic Aeromonas hydrophila from a case of piglet diarrhoea. Zentralblatt fur Veterinarmedizin $B$ 25: 713-718.

Donta S T, Moon H W, Whipp S C 1974 Detection of heatlabile Escherichia coli enterotoxin with the use of adrenal cells in tissue culture. Science 183: 334-336.

Dubey R S, Bhattacharya A K, Sanyal S C 1981 Elevation of adenosine $3^{\prime} 5^{\prime}$ cyclic monophosphate level by Aeromonas hydrophila enterotoxin. Indian Journal of Medical Research 74: 668-674.

Fumarola D, Miragliotta G 1981 Platelet aggregation test and enterotoxins from Yersinia enterocolitica. IRCS Medical Science 9: 1033.

Fumarola D, Miragliotta G 1983 Platelet aggregation test (PAT): an assay system to evaluate enterotoxins. Abstracts of the 83rd Annual Meeting of the American Society of Microbiology, Abstract no. 1399, p. 40.

Fumarola D, Miragliotta G 1984 Aeromonas toxins. Pediatric Infectious Disease 3: 490-491.

Gracey M, Burke V, Robinson J 1982 Aeromonas-associated gastroenteritis. Lancet 2: 1304-1306.

James C, Dibley M, Burke V, Robinson J, Gracey M 1982 Immunological cross-reactivity of enterotoxins of Aeromonas hydrophila and cholera toxin. Clinical and Experimental Immunology 47: 34-42.

Jiwa S F H 1983 Enterotoxigenicity, hemagglutination and cell surface hydrophobicity in Aeromonas hydrophila, Aeromonas sobria and Aeromonas salmonicida. Veterinary Microbiology, 81: 17-34. 
Klipstein F A, Engert R F 1977 Immunological interrelationships between cholera toxin and the heat-labile and heatstable enterotoxins of coliform bacteria. Infection and Immunity 18: 110-117.

Lambin P 1978 Reliability of molecular weight determination of proteins by polyacrylamide gradient gel electrophoresis in the presence of sodium dodecyl sulfate. Analytical Biochemistry 85: 114-125.

Ljungh A, Popoff M, Wadstrom T 1977 Aeromonas hydrophila in acute diarrheal disease: detection of enterotoxin and biotyping of strains. Journal of Clinical Microbiology 6: 96100.

Ljungh A, Wretlind B, Möllby R 1981 Separation and characterization of enterotoxin and two haemolysins from Aeromonas hydrophila. Acta Pathologica et Microbiologica Scandinavica, Section B 89: 387-397.

Pierce N F 1977 Protection against challenge with Escherichia coli heat-labile enterotoxin by immunization of rats with cholera toxin/toxoid. Infection and Immunity 18: 338-341.

Popoff M 1984 Aeromonas Kluyver and Van Niel 1936. In: Krieg N. R. and Holt J. G. (eds) Bergey's Manual of systemic bacteriology vol. 1,9 th edn. Williams and Wilkins Co., Baltimore, 545-548.

Read S M, Northcote D H 1981 Minimization of variation in the response to different proteins of the Coomassie blue $G$ dye-binding assay for protein. Analytical Biochemistry 116: 53-64.

Ruiz-Palacios G M, Torres J, Torres N I, Escamilla E, RuizPalacios B R, Tamayo J 1983 Cholera-like enterotoxin produced by Campylobacter jejuni: Characterisation and clinical significance. Lancet 2: 250-253.

Salzman E W 1972 Cyclic AMP and platelet function. New England Journal of Medicine 286: 358-363.

Sandefur P D, Peterson J W 1977 Neutralization of Salmonella toxir-induced elongation of Chinese hamster ovary cells by cholera antitoxin. Infection and Immunity 15: 988-992.

Satterwhite T K, Evans D G, Dupont H L, Evans D J 1978 Role of Escherichia coli colonisation factor antigen in acute diarrhoea. Lancet 2: 181-184.

Schubert R H W 1967 Die Pathogenität der Aeromonaden für Mensch und Tier. Archiv fur Hygiene und Bakteriologie 150: 709-716.

Shimada T, Sakazaki R, Horigome K, Uesaka Y, Niwano K 1984 Production of cholera-like enterotoxin by Aeromonas hydrophila. Japanese Journal of Medical Science and Biology 37: 141-144.

Wadstrom T, Ljungh A, Wretlind B 1976 Enterotoxin, haemolysin and cytotoxic protein in Aeromonas hydrophila from human infections. Acta Pathologica et Microbiologica Scandinavica 84: 112-114.

Watson I M, Robinson J O, Burke V, Gracey M 1985 Invasiveness of Aeromonas spp. in relation to biotype, virulence factors and clinical features. Journal of Clinical Microbiology 22: 48-51.

Yolken R H, Greenberg H B, Merson M H, Sack R B, Kapikian A Z 1977 Enzyme-linked immunosorbent assay for detection of Escherichia coli heat-labile enterotoxin. Journal of Clinical Microbiology 6 : 439-444. 